\title{
Research on Theme Park's Space Design Based on Cognitive Map Theory: Take Taiji Lake Kung Fu City Theme Park of Wudang Mountains in Hubei as an Example
}

\author{
Han Zang ${ }^{1, a}$, Yong-gang $\mathrm{An}^{2, \mathrm{~b} *}$ and Xiaolin Pang ${ }^{1, \mathrm{c}}$ \\ ${ }^{1}$ The School of Landscape Architecture, Beijing University of Agriculture \\ ${ }^{2}$ Beijing Engineering Research Center of Rural Landscape Planning and Design, Beijing University of Agriculture \\ a737082144@qq.com, bWokaixin75@sina.com, ${ }^{c} 986469376 @ q q . c o m$
}

\begin{abstract}
Under the background of the rise of the national theme park, the design connotation of the theme park, the scientific planning of landscape design and the design of the surrounding environment make the theme park more suitable for the aesthetics of tourists, enhance the satisfaction of tourists, and then improve the theme park. Overall quality. Taking Taiji Lake Kung Fu city theme park of Wudang Mountains in Hubei Province as an example, combined with the important influence of cognitive map theory on park planning, this paper analyzes the design of the Taiji Lake Kungfu City theme park through the five elements of the cognitive map city image, and the Kung Fu City theme park. The construction proposes targeted recommendations and effective design.
\end{abstract}

Keywords: Theme park; cognitive map; planning and design

\section{Foreword}

With the development of the economy and the people's pursuit of quality of life, China's tourism culture industry has received more and more attention. As a new type of tourism project, the theme park has become one of the first choices for leisure and entertainment in leisure time in recent years. It has also become a window for urban tourism, representing the culture and characteristics of the city. [1]

\section{The impact of cognitive map theory on theme park planning and design}

\subsection{The concept of cognitive map and five elements of city image}

Cognitive map is a model similar to a live map generated in the mind based on past experience. Through the processing of the human brain to the environment, a complete model is established in the way to reach the destination. In the early stage of scenic spot planning, using cognitive map theory to plan the scenic spot will be more in line with the psychological needs of tourists. [2]

Among the five elements of urban image, road elements are indispensable components to connect different regions; landmark elements are reference objects with distinct characteristics; node elements are locations connecting different functional zones; regional elements are large spatial ranges with common characteristics; and boundary elements are boundary lines to divide different functional zones. [3]

\subsection{Application of cognitive map theory in theme park planning and design}

Cognitive map theory comes from environmental psychology, and the five elements of urban imagery are important components in cognitive map theory. Using the five elements of urban imagery to reasonably analyze the overall plan of the theme park will undoubtedly make the paradise more humane. In the theme park planning and design, the variety of road paving and architectural styles can make visitors not boring while walking. Applying cognitive map theory to the planning and design of theme parks, the analysis from the perspective of tourists' psychology will make the theme park more in line with the needs of tourists. [4]

\subsection{The advantages of cognitive map theory} combined with theme park planning and design

The application of cognitive map theory to the planning and design of theme parks is mainly to solve the 
following problems more effectively: (1) how quickly and conveniently the tourists arrive at the destination from the location; (2) for valuable and memory points The things that should be placed in order to impress visitors; (3) to create a design to meet the psychological awareness of the theme park. [5]

\section{Case Study of Taiji Lake Kung Fu city theme park of Wudang Mountains in Hubei Province}

\subsection{Project overview}

The project is located at the foot of the northern foot of Wudang Mountain in the north-western part of Hubei Province. It relies on the Taoist holy land of Wudang Mountain in China and the Danjiangkou Reservoir, the largest artificial lake in Asia. The terrain is low and the centre is block-like. The project is built in the mountains. The project covers an area of 80 square kilometres, of which the planned area is 57 square kilometres.

\subsection{Plant essence}

According to the theoretical basis of cognitive maps, combined with environmental psychology, the zoning planning of Taiji Lake Kung Fu city theme park of Wudang Mountains in Hubei Province will enable visitors to have a more comfortable experience.

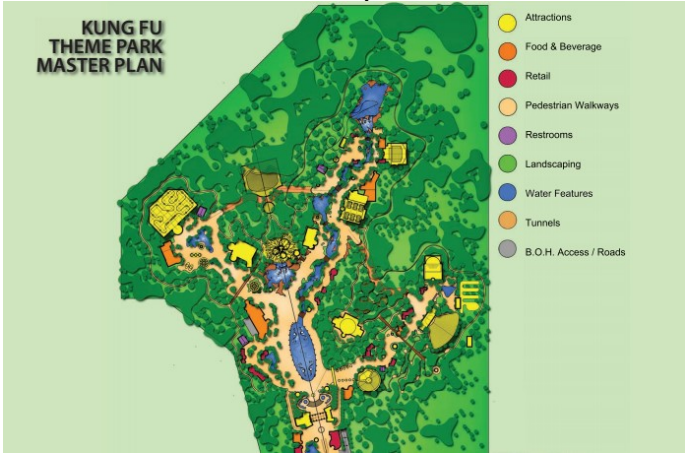

Figure 1. Taiji Lake Kung Fu City theme park plan

Table 1. Taiji Lake Kung Fu City theme park plan.

\begin{tabular}{|c|l|}
\hline \multicolumn{1}{|c|}{ region } & \multicolumn{1}{|c|}{ entry name } \\
\hline \multirow{5}{*}{ EARTH/TRAINING } & $\begin{array}{l}\text { JET LI'S KUNG FU MOVIE } \\
\text { STUDIO }\end{array}$ \\
\cline { 2 - 2 } & $\begin{array}{l}\text { MCDULL'S KUNG FU } \\
\text { SCHOOL }\end{array}$ \\
\cline { 2 - 2 } & $\begin{array}{l}\text { KUNG } \\
\text { STREETMOSPHERE }\end{array}$ \\
\cline { 2 - 2 } & MONKEY KING RIDE \\
\cline { 2 - 2 } METAL/FANTASY & KUNG FU KAROUSEL \\
\hline \multirow{5}{*}{ WATER/BATTLES } & $\begin{array}{l}\text { FANTASY/METAL:CAVE } \\
\text { ENTRANCE }\end{array}$ \\
\cline { 2 - 2 } & $\begin{array}{l}\text { TEMPLE OF } \\
\text { GUARDIANS THE }\end{array}$ \\
\hline & $\begin{array}{l}\text { THE WARRIOR'S } \\
\text { BATTLEGROUND }\end{array}$ \\
\cline { 2 - 2 } & VR KUNG FU WARRIORS \\
\cline { 2 - 2 } & THE WATERSHOT \\
\cline { 2 - 2 } & KUNG \\
\hline
\end{tabular}

\begin{tabular}{|c|c|}
\hline & $\begin{array}{l}\text { SIMULATOR } \\
\text { ADVENTURE }\end{array}$ \\
\hline & $\begin{array}{ll}\text { GREAT } & \text { BATTLES } \\
\text { THEATER } & \end{array}$ \\
\hline & $\begin{array}{l}\text { THE BATTLE } \\
\text { COASTER }\end{array}$ \\
\hline \multirow{3}{*}{ WOOD/CULTURE } & DESTINY'S PATHWAY \\
\hline & KUNG FU MUSEUM \\
\hline & SURROUDSORIUM \\
\hline \multirow{7}{*}{ FIRE/MASTER } & CAVE OF THE ELEMENTS \\
\hline & THE WAY \\
\hline & $\begin{array}{l}\text { LEGEND OF } \text { ZHANG } \\
\text { SANFENG } \\
\text { :KUNG FU LIVE SHOW }\end{array}$ \\
\hline & BAMBOO \\
\hline & GAUNTLET \\
\hline & THE ARMORY \\
\hline & $\begin{array}{l}\text { FLIGHT TO WUDANG } \\
\text { MOUNTAIN 3D }\end{array}$ \\
\hline
\end{tabular}

\subsubsection{The five elements of cognitive map-Boundary and regional elements}

First of all, the theme park is divided into four major areas - the play area, the natural area, the artificial scene and the service area. Secondly, for the difference of the functions of various amusement facilities, the play area of the Kung Fu City theme park is divided into five areas according to the order of tourists: metal, wood, water, fire and earth. The theme of the "Metal" area is the temple with Chinese elements; the "Wood" area is mainly the area of cultural inheritance and innovation; the "Fire" area mainly includes Kung Fu performance show, 3D studio, bamboo forest adventure, etc.; The main function is for children's entertainment.

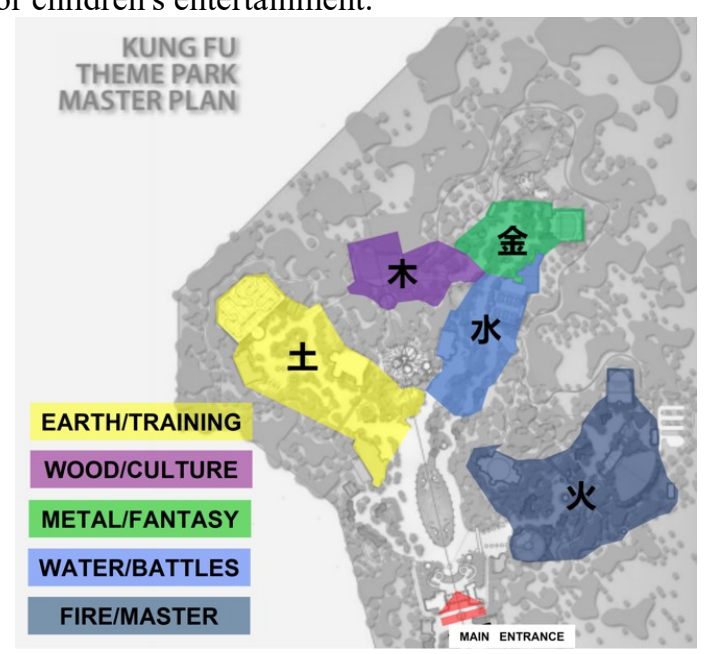

Figure 2. Taiji Lake Kung Fu City theme park important area division

\subsubsection{The five elements of cognitive map-the leading element of roads}

(1) The main road is a battery car and pedestrian passage from the gate of the scenic spot to the fountain in the center of the scenic spot. It is mainly used for pedestrians and battery vehicles. At the same time, this road is also a fire lane, so it is relatively wide. 
(2) The secondary trunk road is a road leading to the various areas from the central fountain of the scenic spot. It is also a passage for power supply bottles and pedestrians, but the flow of people is diverted at the central fountain, so it is narrower than the main road.

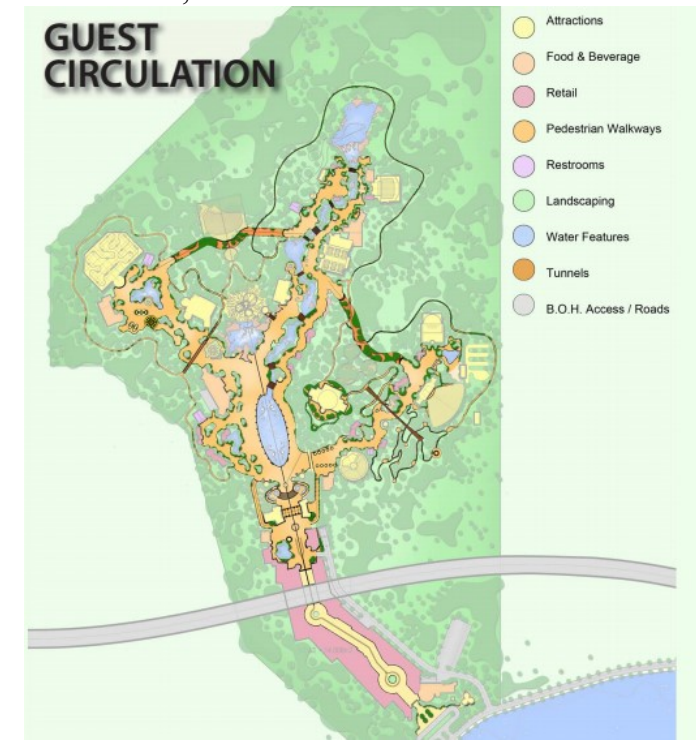

Figure 3. Taiji Lake Kung Fu City theme park road system

\subsubsection{The five elements of cognitive map-functional elements of node planning}

This design makes a clear plan for important nodes. In the design, the guidance system at the node is mainly set for the identification guiding function, and the iconic graphic symbols are used on the path to attract the tourists' high attention, minus the unnecessary words that the tourists are not willing to read, and the guiding system is used. A more concise symbol to replace, to achieve a high degree of recognition.

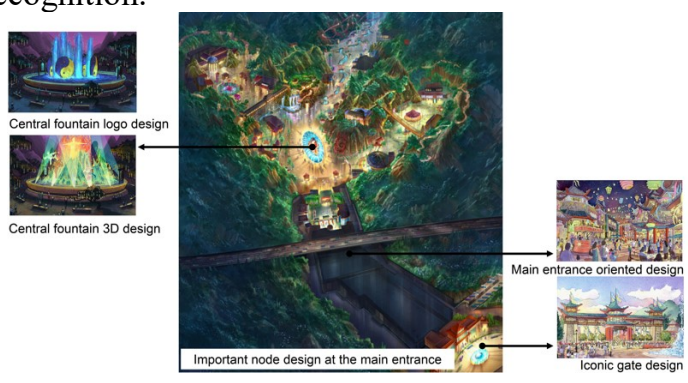

Figure 4. Main entrance important node design

\subsubsection{The five elements of cognitive map-design elements of landmark IP}

The design of Taiji Lake Kung Fu City Theme Park has a strong logo IP feature. It uses the image of traditional Chinese Kung Fu Wudang to create a theme park with the theme of Wudang Kungfu. And set up Kung Fu landmarks in the park. At the same time pay attention to the details of the treatment, the building's city wall adopts the pattern of ancient red brick and green tiles. The architectural style adopts the style of ancient temples, and the creation of various eaves makes visitors feel like they are in the ancient city of Kung Fu.

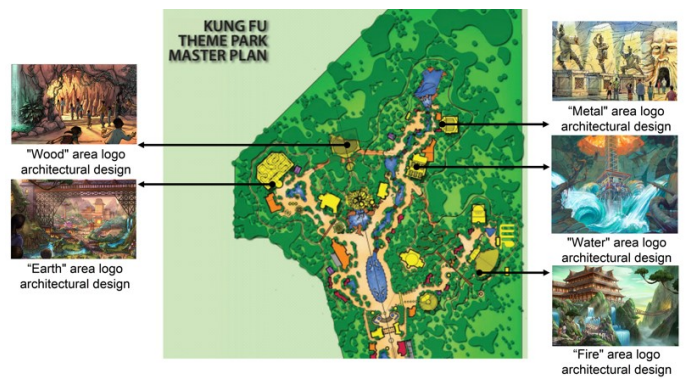

Figure 5. Landmark construction design of Taiji Lake Kung Fu City Theme Park

\section{Summary}

In the planning of the Taiji Lake Kung Fu City theme park, based on the five elements of the cognitive map, the design analysis of the park, and through the extraction of cultural elements, the key planning and analysis of the internal IP image and guidance system of the theme park. The research on Taiji Lake theme park is still limited. The space guidance system is an important part of the theme park. Its development needs all aspects of support and cooperation to get the best planning plan.

\section{Acknowledgement}

This project consists of Scientific and Technological Innovation Service Capacity Building-Scientific Research Base Construction-Eco-environmental Function Promotion Collaborative Innovation Center of Forest and Fruit Industry (2011 Collaborative Innovation Center) (Municipal Level), the project code for 2018 ( NO.PXM2018 014207000024 ).2018 connotation development quota project - improvement of students' comprehensive quality - students' connotation development project(NO.5056516008/042).This work was supported by grants from the Beijing Municipal Education (CEFF-PXM2018_014207_000024).

Commission

\section{References}

1. Wang Danni. Theme park guidance system function analysis [J]. design, 2016, (3): 142-143. (2016)

2. Tan Wen di. Huaqiao University campus environmental cognitive map research [D]. Huaqiao University: Wang Zhijun. (2007)

3. Li Juan. Research on the Adaptive Renewal of Outer Space of Historical Blocks Based on Environmental Psychology [D]. Chongqing University: Li Heping. (2011)

4. Liu Jianrong. Say trees in bonsai art [J]. Gansu forestry, 2001, (1). (2001)

5. Hu Jiujie. Research on Landscape Design of Theme Parks - Application of Behavioral Psychology in Landscape Design of Theme Parks [D]. Nanjing Forestry University: Yin Anshi.(2008) 